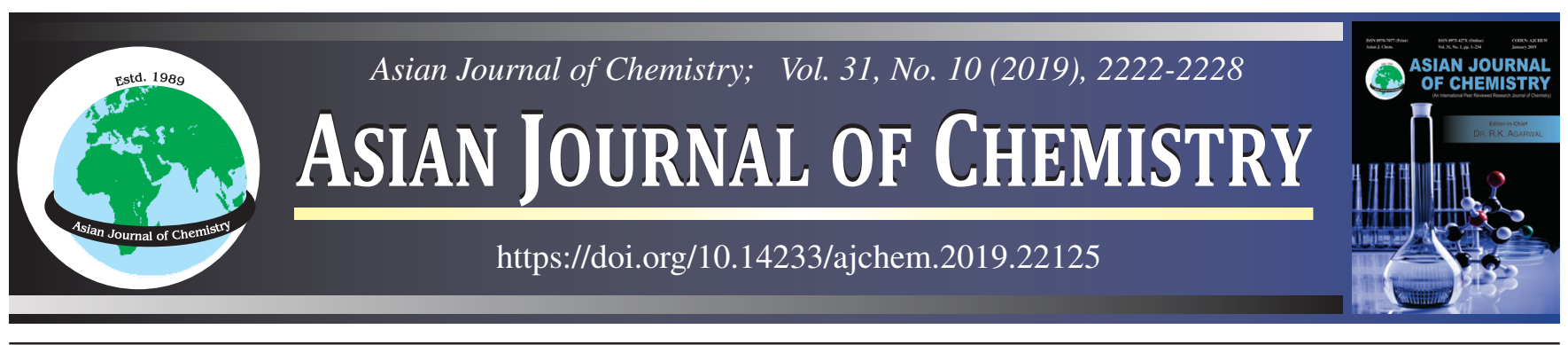

\title{
Structural, Optical and Photocatalytic Properties of PEG Assisted CdO Nanoparticles by Co-Precipitation Method
}

\section{Elayaraja ${ }^{1}$, I. Kartharinal Punithavathy ${ }^{1,{ }^{*},}$ S. Johnson Jeyakumar ${ }^{1}$, M. Jothibas ${ }^{1}$ and C. Manoharan $^{2}$}

${ }^{1}$ P.G. \& Research Department of Physics, T.B.M.L. College, Porayar-609307, India

${ }^{2}$ Department of Physics, Annmalai University, Annmalai Nagar-608002, India

*Corresponding author: E-mail: profpunithaphysics@gmail.com; elayarajaphy2017@gmail.com

| A simple and modified chemical precipitation method is used for synthesis of different PEG assisted cadmium oxide nanoparticles. The prepared products were characterized by X-ray diffraction, Fourier transform infrared, ultraviolet, scanning electron microscopy and energy dispersive X-ray analysis. The XRD patterns revealed the cubic phases and calculated particle sizes are $36.42,34.27,33.54$ and $35.21 \mathrm{~nm}$ for pure $\mathrm{CdO}$ with 2, 4 and $6 \%$ PEG nanoparticles respectively, From these results, it can be observed that the average crystalline size decreases with increasing PEG concentration. The functional groups and band area of the product were established by FTIR spectroscopy. The band gap energy of CdO nanoparticles increased from 2.54 to $2.94 \mathrm{eV}$ by increasing PEG concentration .The surface morphology and element composition have been confirmed form SEM with EDX analysis. In addition, the photocatalytic performance of PEG assisted $\mathrm{CdO}$ nanoparticles with methylene blue indicated that the $\mathrm{CdO}$ can be utilized a good photocatalyst for degradation of methylene blue.

Keywords: Co-precipitation, Cadmium oxide, Nanoparticles, Methylene blue.

ᄂ

\section{INTRODUCTION}

Nanotechnology is the manipulation of matter on an atomic, molecular and super molecular scale, ranging in dimensions 1 to $100 \mathrm{~nm}$. It is an important area in recent research due to its immense use in the different field of science [1]. Nanoparticles the characteristic properties such as increased surface area, size and morphology are dissimilar and become better when compared to the bulk counterparts. Nano of conducting oxides have attracted the attention of researchers over the last two decades due to their outstanding application in solar cells, flat panel displays, photovoltaic devices, smart windows and possible applications in magnetic fluids, catalysis, biotechnology, medical imaging technique and date storage [2].

Metal oxide nanoparticles for instance, zinc oxide, tin oxide, indium oxide, ultra fine titanium oxide and cadmium oxide are reported earlier [3]. The metal oxide nanoparticles play a significant role in degradation of n-type semiconductor materials and cadmium oxide is a remarkable one having $\mathrm{NaCl}$ structure which has a cubic unit cell in $\mathrm{Cd}$ and $\mathrm{O}$ atoms placed in a lattice points. One account of this attracting adsorption of new techniques, some attempts have been taken to make use of these $\mathrm{CdO}$ nanoparticles in different areas of study [4,5]. Numerous synthesis method for physical and chemical synthesis procedures such as sol-gel synthesis, hydrothermal, template assisted, solvothermal, mechano-chemical, thermal decomposition, photosynthetic and sonochemical approaches have been taken up to put together $\mathrm{CdO}$ nanoparticles [6]. Here, we have preferred the strategy of chemical precipitation for the amalgamation of metal oxide nanoparticles. Because, it is easy to control the particle size, a low temperature process, low cost method and the smallest nanoparticles with good optical properties, in comparison with other methods of the synthesis [7].

Surfactant active substance has good scientific significance due to number of succeeding usages in cleaning agents. Among other areas, surfactants in addition, have scientific interests in the fields of physical chemistry and biology [8]. Further, the surfactant of PEG is important to study at the water interface because of their relevance in diverse areas of funda-

This is an open access journal, and articles are distributed under the terms of the Attribution 4.0 International (CC BY 4.0) License. This license lets others distribute, remix, tweak, and build upon your work, even commercially, as long as they credit the author for the original creation. You must give appropriate credit, provide a link to the license, and indicate if changes were made. 
mental chemistry $[9,10]$. It appears that a very dilute impurity in the PEG surfactant can greatly affect nanorod formation.

Polyethylene glycol (PEG) is a commonly used approach for improving the efficiency of photocatlytic degradation and it is one of the polymers which is a chemical compound formed by polymerization. It is an interesting area of study since it is harmless and safe but not catching fire easily and automatically and also easy handle. At the superficial aspect of metal oxide collide is formed that PEG with unvarying and organized structure has been carefully noted [11]. Hence, it remains an important chal-lenge to capped PEG into $\mathrm{CdO}$ nanoparticles

Cadmium oxide has been extensively studied because of its high photocatalytic activity, low cost, abundant availability and so on. Therefore, the aim of the present study is to synthesize the pure and PEG assisted CdO nanoparticles via chemical precipitation method. Moreover, the photocatalytic activity of PEG capped CdO nanoparticles on methylene blue dye have been studied under sun light illumination.

\section{EXPERIMENTAL}

All the chemical reagents used were of analytically (AR grade) pure. Cadmium acetate hexahydrate, polyethylene glycol (PEG-5000-7000) and ammonium hydroxide were obtained with $99 \%$ purity from Nice Chemical company and used without further purification.

Synthesis of PEG assisted CdO nanoparticles: In a typical synthesis, $0.2 \mathrm{M}$ of cadmium acetate, $\mathrm{PEG}$ and $1.2 \mathrm{M}$ of $\mathrm{NH}_{4} \mathrm{OH}$ were chosen. Polyethylene glycol (2, 4 and $6 \%)$ were dissolved in $25 \mathrm{~mL}$ of deionized water then added to $100 \mathrm{~mL}$ aqueous solution of cadmium acetate. Further, $100 \mathrm{~mL}$ solution of ammonia (1.2 M) was added with dropwise to the precursor's solution. After that the mixed solution was stirred at room temperature for $2 \mathrm{~h}$. The resultant precipitant was filtered and washed with deionized water and acetone for many times. Then, it was dried at $100^{\circ} \mathrm{C}$ for $6 \mathrm{~h}$ in hot air oven and grounded using mortar to remove agglomerates. The resulting powder was annealed at $400{ }^{\circ} \mathrm{C}$ for $2 \mathrm{~h}$ in muffle furnace to get brown colour $\mathrm{CdO}$ nanoparticles. The obtained sample was powered in an agate mortar for characterization.

Characterizations: The crystalline phase purity of $\mathrm{CdO}$ with different PEG concentrations was examined by X-ray diffraction analysis using SHIMADZU $6000 \mathrm{X}$-ray diffractometer with $\mathrm{CuK} \alpha$ radiation $(\lambda=1.5406 \AA)$ at room temperature. The chemical structure was investigated by Shimadzu Fourier transform infrared spectrophotometer in which the IR spectrum was recorded by diluting the milled powder in $\mathrm{KBr}$. And the wavelength between 4000 and $400 \mathrm{~cm}^{-1}$ was used to assess the presence of functional groups in $\mathrm{CdO}$. Optical absorption spectrum was recorded in the range $300-1200 \mathrm{~nm}$ using JASCO C-670 spectrophotometer. The morphology and composition of the products were investigated by SEM with EDX analysis with a JEOL JSM 6390.

Photocatalytic activity: The photocatalytic activities of pure $\mathrm{CdO}$ samples were evaluated by monitoring the photo degradation of methylene blue in aqueous solution. Methylene blue was selected because of its strong adsorption to metal oxide surfaces well defined optical absorption a good resistance to light degradation. The photocatalytic experiments were carried out on sunny days betweeen 11 am and $2 \mathrm{pm}$. The photocatalyst of pure $\mathrm{CdO}(0.06 \mathrm{~g})$ was charged into $100 \mathrm{~mL}$ of $10 \mathrm{mg} / \mathrm{L}$ methylene blue aqueous solution, respectively. The solution was magnetically stirred for $30 \mathrm{~min}$ to attain adsorption-desorption equilibrium between dye and $\mathrm{CdO}$. The mixed solutions were irradiated using sunlight. The solutions were then taken out every $20 \mathrm{~min}$ (upto $120 \mathrm{~min}$ ) and the photocatalyst was separated from the mixture solution by centrifugation immediately, and then the UV-Vis spectrophotometer (Shimadzu, UV-1800). The absorbance of methylene blue solution was measured at $664 \mathrm{~nm}$, which corresponds to its maximum absorption wavelength.

\section{RESULTS AND DISCUSSION}

XRD analysis: The powder X-ray diffraction patterns of $\mathrm{CdO}$ nanoparticles with various $\mathrm{PEG}$ concentrations are shown in Fig. 1. All the observed peaks are attributed to the characteristic peaks of CdO (JCPDS-ICCD card: 75-0592). The diffraction peaks with $2 \theta=33.080^{\circ}, 38.250^{\circ}, 55.260^{\circ}, 65.660^{\circ}$ and $69.700^{\circ}$ correspond to the crystal planes of (111), (200), (220), (311) and (222) of CdO face centered cubic phase, respectively [12]. The absence of impurity peaks in the XRD patterns indicating the purity of product. The average crystallite size was estimated from the intense peaks (1110) using Scherer's equation [13]:

$$
\mathrm{D}=\frac{\mathrm{k} \lambda}{\beta \cos \theta}
$$

where, $\mathrm{K}$ is a constant (0.9), $\lambda$ is the wavelength of $\mathrm{CuK} \alpha$ radiation (1.5406 $\AA$ ), $\theta$ is the peak position and $\beta$ is the full width at half maximum (FWHM).

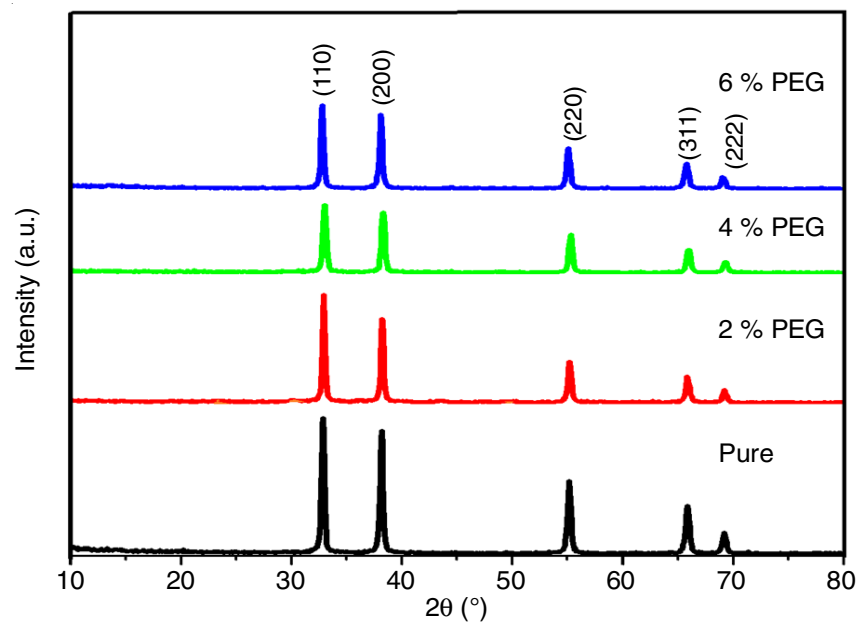

Fig. 1. XRD patterns of pure-CdO, $2 \%$ PEG-CdO, $4 \%$ PEG-CdO and 6 $\%$ PEG-CdO nanoparticles

The mean crystallite sizes of $\mathrm{CdO}$ and 2, 4 and $6 \%$ of PEG with $\mathrm{CdO}$ are $36.42,34.27,33.54$ and $35.21 \mathrm{~nm}$, respectively. The PEG assisted $\mathrm{CdO}$ products show decreased crystallite sizes when compared to pure $\mathrm{CdO}$. The intensities of all the peaks continuously increased with increasing PEG concentration. The result indicates that inactive PEG atoms in $\mathrm{CdO}$ nanoparticles have been segregated into grain boundaries and to restrict the crystallization and preferred orientation of $\mathrm{CdO}$ nanoparticles. The reduction of particles size from 36.42 to $33.54 \mathrm{~nm}$ on $4 \%$ of PEG reveals its optimum level. No apparent 
diffracting peaks of any other minerals can be detected in the XRD patterns. Absence of characteristic peaks of PEG in XRD pattern indicating the PEG has immersed in to $\mathrm{CdO}$ nanoparticles matrixes. In order to get nanocrystallite sizes decreased the final results confirmed the PEG has been possibly enchanced the crystallinity and it is extremely relevant to the full width at half maxima (FWHM) value $[14,15]$.

Functional group analysis: The analysis of multi-component systems to provide information concerning the materials phase composition and types of interactions existing among the cadmium molecules is confirmed by FT-IR spectrum in the wavelength region of $4000-400 \mathrm{~cm}^{-1}$ [16]. Fig. 2 shows the FT-IR spectra for pure and PEG assisted CdO nanoparticles. The strong transmission bands at 3720, 3051, 2945 and $2869 \mathrm{~cm}^{-1}$ are assigned to $\mathrm{C}-\mathrm{H}$ asymmetric stretching vibration. The peaks at $2869 \mathrm{~cm}^{-1}$ can attribute to the absorption of $\mathrm{CO}_{2}$ molecule. This result indicates that the good variations between the pure and PEG $(2,4$ and $6 \%)$ assisted $\mathrm{CdO}$ nanoparticles [17]. The bands at 1394 and $1517 \mathrm{~cm}^{-1}$ can be ascribed as the bending vibrations of $\mathrm{C}-\mathrm{N}$ stretching of benzenoid structure and in-plane $\mathrm{C}-\mathrm{H}$ bending of quinoid structure, respectively [18]. IR spectra shows characteristic absorption peaks at 511 and $651 \mathrm{~cm}^{-1}$. The band observed around $554 \mathrm{~cm}^{-1}$ is attributed to $\mathrm{Cd}-\mathrm{O}$ of $\mathrm{CdO}$ confirms the formation of pure $\mathrm{CdO}$ nanparticles [19]. The peaks at $651 \mathrm{~cm}^{-1}$ indicates the vibrations of $\mathrm{Cd}-\mathrm{OH}$ groups.

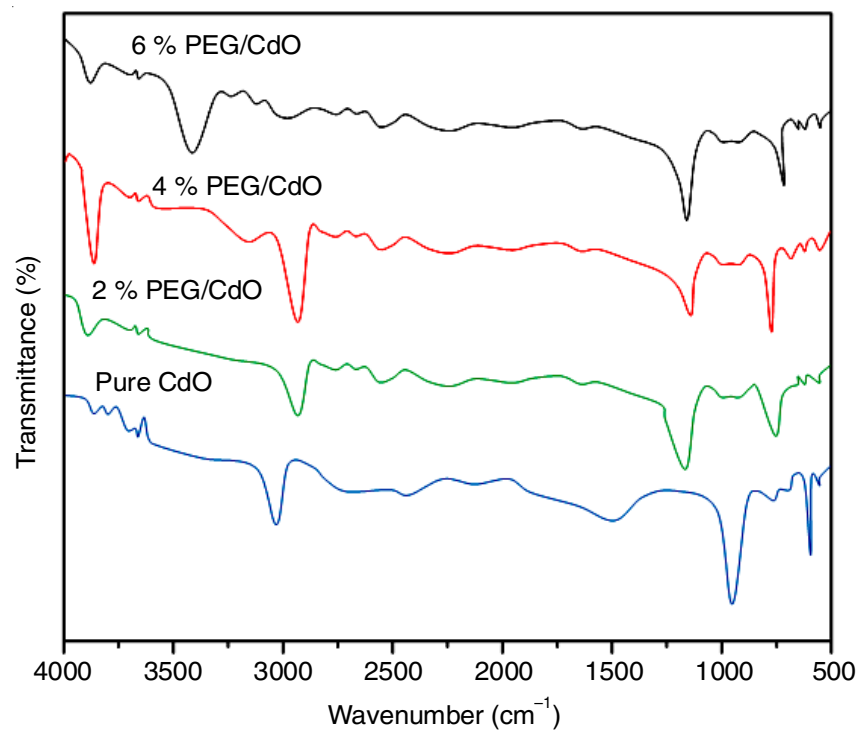

Fig. 2. FTIR spectra of pure-CdO, $2 \%$ PEG-CdO, $4 \%$ PEG-CdO and 6 $\%$ PEG-CdO nanoparticles

Optical properties: The absorption spectra of pure $\mathrm{CdO}$ and PEG capped $\mathrm{CdO}$ nanoparticles were recorded to investigate the optical properties. Fig. 3 shows the UV-DRS absorption spectra of the prepared samples. The pure $\mathrm{CdO}$ nanoparticles shows an excitonic absorption edge at $487 \mathrm{~nm}$ whereas the adsorption peak of PEG (2, 4 and $6 \%)$ assisted CdO nanoparticles were shifted to 432,421 and $437 \mathrm{~nm}$, respectively. The transparency in the visible range of $\mathrm{CdO}$ nanoparticles with increasing PEG concentration. The value of optical band gap is determined from the absorption spectra using the Tauc relation:

$$
\alpha h v=A\left(h v-E_{g}\right)^{n}
$$

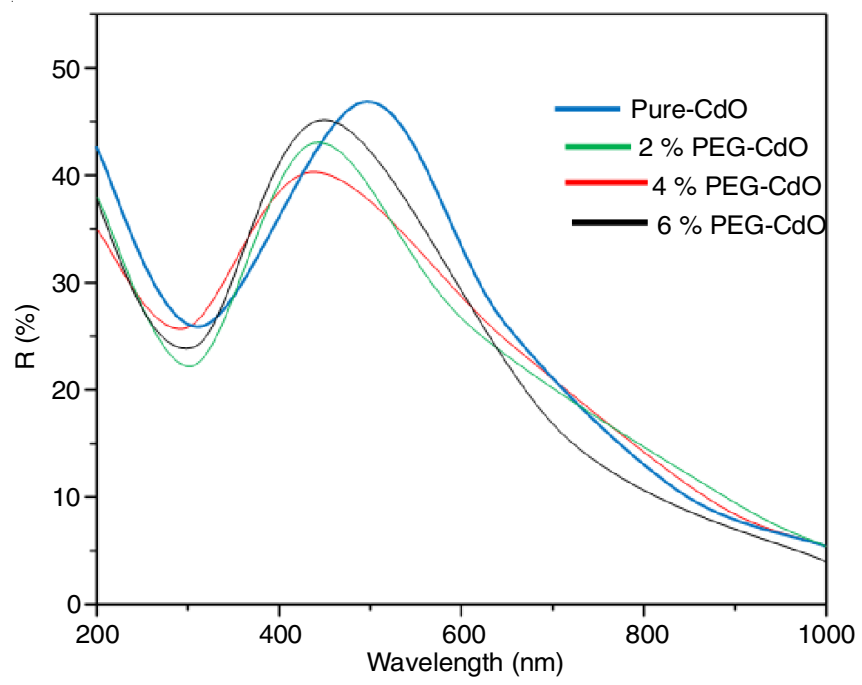

Fig. 3. UV-visible spectra of pure-CdO, $2 \%$ PEG-CdO, $4 \%$ PEG-CdO and $6 \%$ PEG-CdO nanoparticles

where, $\alpha$ is the absorption coefficient, A is having separate value for different transitions, $h v$ is the photon energy and $E_{g}$ is the band gap energy. The values of $\mathrm{n}$ depend upon the nature of transition. The values $\mathrm{n}$ of direct tradition in the allowed state are $1 / 2,2,3 / 2$ and 3 respectively. Fig. $4(\alpha h v)^{2}$ versus $h v$ shows the curves of $\mathrm{CdO}$ nanoparticles in different PEG concentrations. The diagonal portions of the map are comparable to $\mathrm{x}$-axis. The energy band spaces measured from these layers are represented in Table-1. $\mathrm{E}_{\mathrm{g}}$ values are 2.61 to $2.87 \mathrm{eV}$ for PEG assisted nanoparticles in different concentrations.

Microstructural and elemental analyses: The surface morphology of $\mathrm{CdO}$ and 2, 4, 6 \% PEG assisted $\mathrm{CdO}$ sample

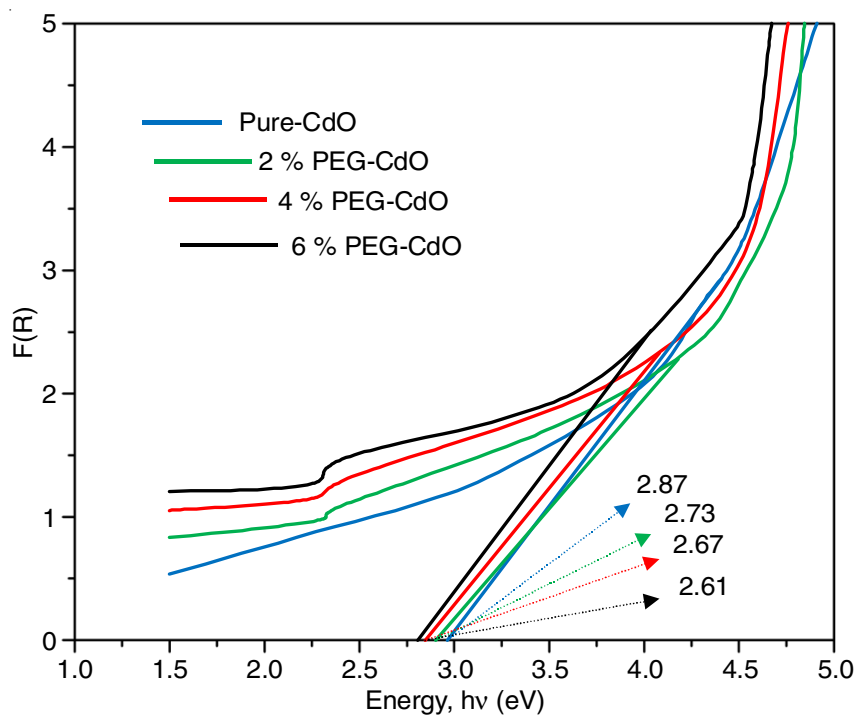

Fig. 4. Band gap spectra of pure-CdO, $2 \%$ PEG-CdO, $4 \%$ PEG-CdO and $6 \%$ PEG-CdO nanoparticles

TABLE-1

OPTICAL BAND GAP OF PURE WITH PEG ASSISTED

\begin{tabular}{cc}
\hline Samples & Band gap $(\mathrm{eV})$ \\
\hline Pure & 2.87 \\
PEG $(2 \%)$ CdO & 2.73 \\
PEG $(4 \%)$ CdO & 2.67 \\
PEG $(6 \%)$ CdO & 2.61 \\
\hline
\end{tabular}


was examined by SEM analysis. In Fig. 5a, SEM images exhibited the spherical shape with aggromation for $\mathrm{CdO}$ as well as PEG added $\mathrm{CdO}$ nanoparticles [20].The surface morphology of $\mathrm{CdO}$ nanoparticles were changed considerables as adding different concentrations of PEG. The grain size in pure $\mathrm{CdO}$ is estimated to be about $34-39 \mathrm{~nm}$. Thus, SEM images suggest that the nanoparticles showing crystalline nature for higher PEG capping and the particles become amorphous for lower concentration of PEG. Also, the surface is well covered with grains that are almost uniformly distributed over the surface. Fig. 5b depicts the surface occupancy plot (SOP) of pure and 2, 4 and $6 \%$ PEG assisted $\mathrm{CdO}$ nanoparticles.

The EDX spectra is shown in Fig. 6 and the peaks corresponding to $\mathrm{Cd}$ and $\mathrm{O}$ elements were presented along with $\mathrm{Cu}$ peaks coming from the some impurity. The elements in the atomic ratio, $\mathrm{Cd}=59.15 \%, \mathrm{O}=38.09 \%$ and $\mathrm{Cu}=2.76 \%$ can be observed for the presented samples.

Photocatalytic activity: The accomplishment of photocatalysis relies on crstallinity which refers to the degree of structural order solid. In a crystal the molecules are arranged in regular in periodic manner. The degree of crystallity has a big influence on hardness density, transparency and diffusion. It also depends on outer part and study of the form and structure of organism and their specific structural features i.e. morphology. It is again intensified or increased in value by demising the combining of charges or transfer of electrons in a metal that results in the neutralization of ions and the photogenerated electron hole-pairs which are produced by thermal energy. It leads to the arousal of electromagnetic wave or the wavelength i.e., the distance between peaks to a lower energy range $[21,22]$. Thus it enhanced the amount of reactions on surface. The reaction in which atleast one of the steps of the reaction mechanism is the absorption of one or more reactants.

As a rule, the procedure for photocatalysis starts when supraband gap photons are specifically assimilated therefore producing electron-hole pairs in the semiconductor particles. This is followed by diffusion of charge carriers to the particle surface where the interaction with water molecules would produce highly reactive species of peroxide $\left(\mathrm{O}_{2}\right)$ and hydroxyl radical $(\mathrm{OH})$ responsible for the degradation of adsorbed organic molecules. The process of photocatalytic degradation of methylene blue over $\mathrm{CdO}$ catalyst can be described as follows: The first step involves adsorption of the dye onto the surface of $\mathrm{CdO}$ nanostructure sample exposure hole $\left(\mathrm{e}^{-}-\mathrm{h}^{+}\right)$pairs in $\mathrm{CdO}$. The photo-generated electrons in the conduction band of $\mathrm{CdO}$ interact with the oxygen molecules adsorbed on $\mathrm{CdO}$ to form superoxide anion radicals $\left({ }^{*} \mathrm{O}_{2}\right)$.

The hole produced in the permissible energy values that are the highest energies an electron can have associated with a particular atom of a solid material of $\mathrm{CdO}$ change with the exterior entity with the formula $\mathrm{OH}$. It contains oxygen bonded
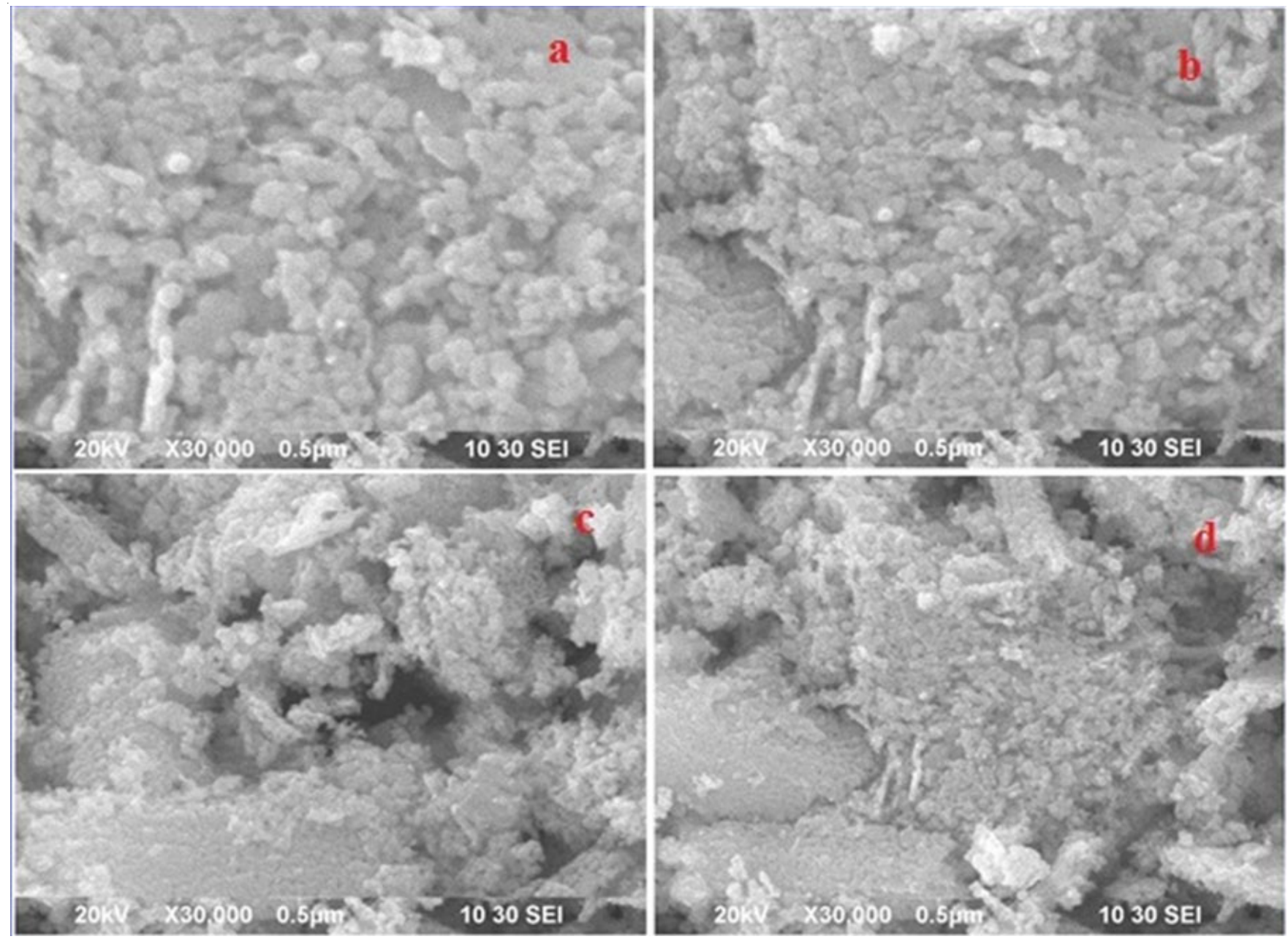

Fig. 5a. SEM image of (a) pure and (b) $2 \%$ PEG-CdO, (c) $4 \%$ PEG-CdO and (d) 6\% PEG-CdO nanoparticles at 30000x 

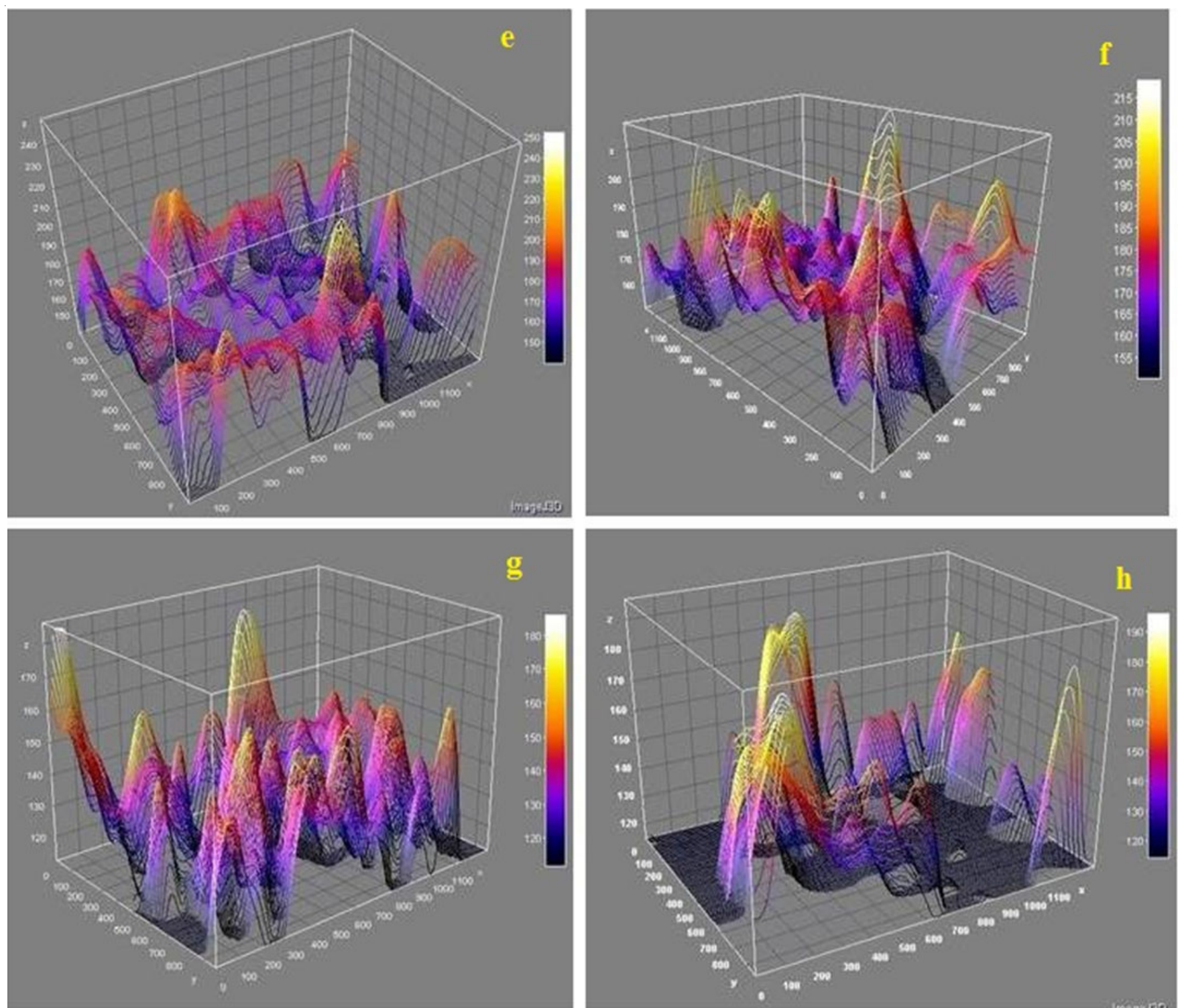

Fig. 5b. Surface occupancy plot (SOP) of (e) pure and (f) $2 \%$ PEG-CdO, (g) $4 \%$ PEG-CdO and (h) 6\% PEG-CdO nanoparticles
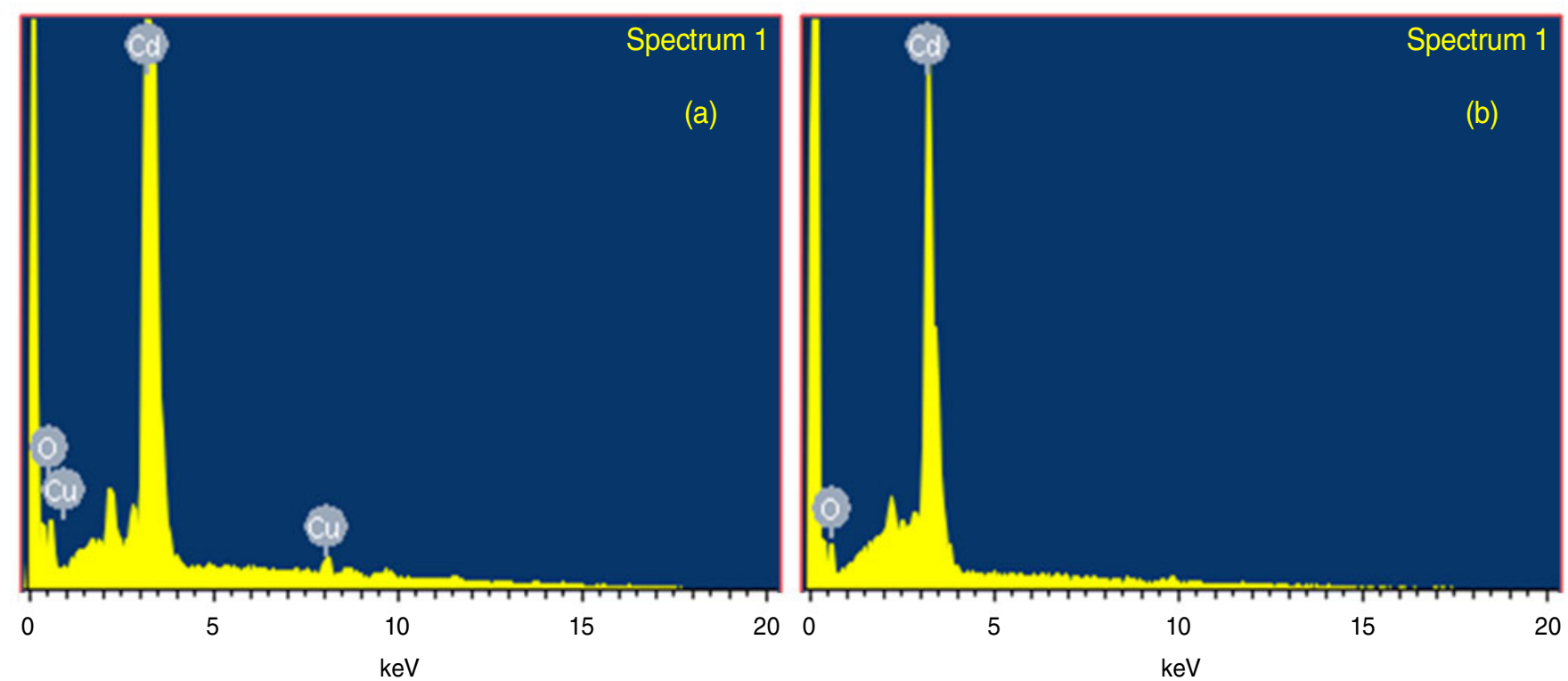

Fig. 6. EDX spectra for (a) pure $\mathrm{CdO}$ and (b) PEG-CdO nanoparticles 
to hydrogen as in alcohol and carboxylic acid contains hydroxyl groups. The photon produced opening will results in the separation of whole segments of the molecules of water in the solution of water-making radicals hydroxyl radicals are easily becoming hydroxyl [23]. It is the most reactive oxygen species and can react effectively. The superoxide radicals is only meditatively reactive with methylene blue due engrossed on $\mathrm{CdO}$. The structure of intermediate size between microscopic and molecular structures that the way for its process of damaging and degradation.

$$
\begin{gathered}
\mathrm{CdO}+\mathrm{h} v \longrightarrow \mathrm{e}^{-}(\mathrm{CB})+\mathrm{h}^{+}(\mathrm{VB}) \\
\mathrm{O}_{2}+\mathrm{e}^{-} \longrightarrow \mathrm{O}_{2}{ }^{*-} \\
\mathrm{h}^{+}+\mathrm{OH}^{-} \longrightarrow \mathrm{OH}^{*} \\
\mathrm{~h}^{+}+\mathrm{H}_{2} \mathrm{O} \longrightarrow \mathrm{H}^{+}+\mathrm{OH}^{-*}
\end{gathered}
$$

${ }^{*} \mathrm{OH}^{-}$Methylene blue $\longrightarrow$ Degradation products

$* \mathrm{O}_{2}{ }^{-}+$Methylene blue $\longrightarrow$ Degradation products

The degradation percentage ( $\% \mathrm{D})$ of methylene blue dye can be calculated from the following equation [24]:

$$
\mathrm{D}(\%)=\frac{\mathrm{C}_{\mathrm{o}}-\mathrm{C}_{\mathrm{t}}}{\mathrm{C}_{\mathrm{o}}} \times 100
$$

where $\mathrm{C}_{\mathrm{o}}$ is the initial concentration of dye and $\mathrm{C}$ is the concentration of dye after irradiation at selected time intervals (0-120 min). Several experimental results suggest that the rates of oxidation of various contaminants over illuminated $\mathrm{CdO}$ occur via pseudo first-order kinetics [25].

$$
\ln \left(\mathrm{C}_{\mathrm{o}} / \mathrm{C}_{\mathrm{t}}\right)=\mathrm{kKt}=\mathrm{kt}
$$

$$
\mathrm{C}_{\mathrm{t}}=\mathrm{C}_{\mathrm{o}} \mathrm{e}^{-\mathrm{kt}}
$$

where $\mathrm{k}$ is the reaction rate constant and $\mathrm{K}$ is the adsorption coefficient of the reactant. A plot of $\ln \left(\mathrm{C}_{\mathrm{o}} / \mathrm{C}_{\mathrm{t}}\right)$ versus time represents a straight line; the slope equals the apparent first order rate constant $\mathrm{k}$.

Fig. 7 shows the absorption spectra of methylene blue using pure $\mathrm{CdO}$ catalyst as a function of wavelength $(400-800 \mathrm{~nm})$ for various time intervals $0,20,40,60,800,100$ and $120 \mathrm{~min}$ the degradation effect was characterized by monitoring the absorption peak of methylene blue centered at $664 \mathrm{~nm}$. The plots clearly demonstrate that the maximum absorption peak decreases with increasing irradiation time. This illustrates that the methylene blue concentration decreases in the presence of pure $\mathrm{CdO}$ catalyst and solar light illumination. The decrease in the absorption of mixed solution was due to the destruction of homo- and heteropoly aromatic rings present in methylene blue or due to rapid degradation of methylene blue, which is confirmed by the lower intensities of absorbance peak of methylene blue. The effect of pure $\mathrm{CdO}$ catalysts on percentage degradation of methylene blue dye has been examined by varying the time interval from 0 to $120 \mathrm{~min}$ and the results are presented in Table-2. The percentage degradation increases rapidly with the increase in the time for methylene blue-catalyst solutions. The maximum degradation of methylene blue dye took place in 120 min of irradiation with sunlight using pure $\mathrm{CdO}$ catalysts was $71.98 \%$, while in the case of time at 20 min, only $22.26 \%$ degradation was observed for pure $\mathrm{CdO}$ catalysts, respectively.

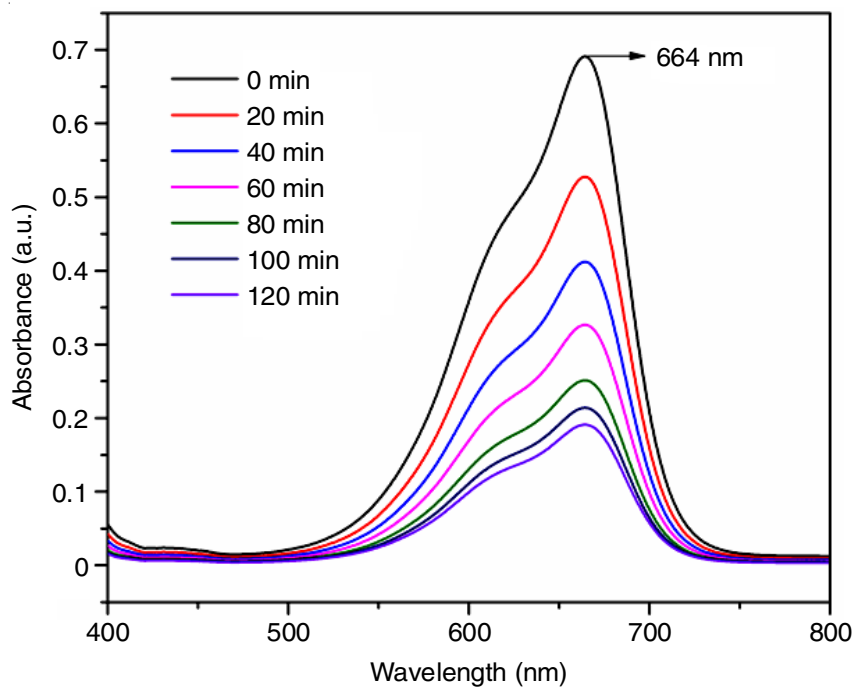

Fig. 7. UV-visible absorption spectra of methylene blue with respect to irradiation time using $\mathrm{CdO}$ photocatalyst

TABLE-2

EFFECT OF METHYLENE BLUE

DEGRADATION BY CdO PHOTOCATALYSTS

Time Degradation of methylene blue $(\%)$

$\begin{array}{cc}0 & 0 \\ 20 & 22.26 \\ 40 & 39.26 \\ 60 & 51.86 \\ 80 & 63.15 \\ 100 & 69.04 \\ 120 & 71.98\end{array}$

According to pseudo-first-order rate equation, the rate constant $(\mathrm{k})$ for degradation by pure $\mathrm{CdO}$ was determined. The plot of In $\left(\mathrm{C}_{\mathrm{o}} / \mathrm{C}_{\mathrm{t}}\right)$ as a function of irradiation time gives the rate constant value $0.0084 \mathrm{~min}^{-1}$ (Fig. 8). Moreover, the fitting correlation co-efficient $\left(\mathrm{R}^{2}\right)$ is also determined to be 0.9451 .

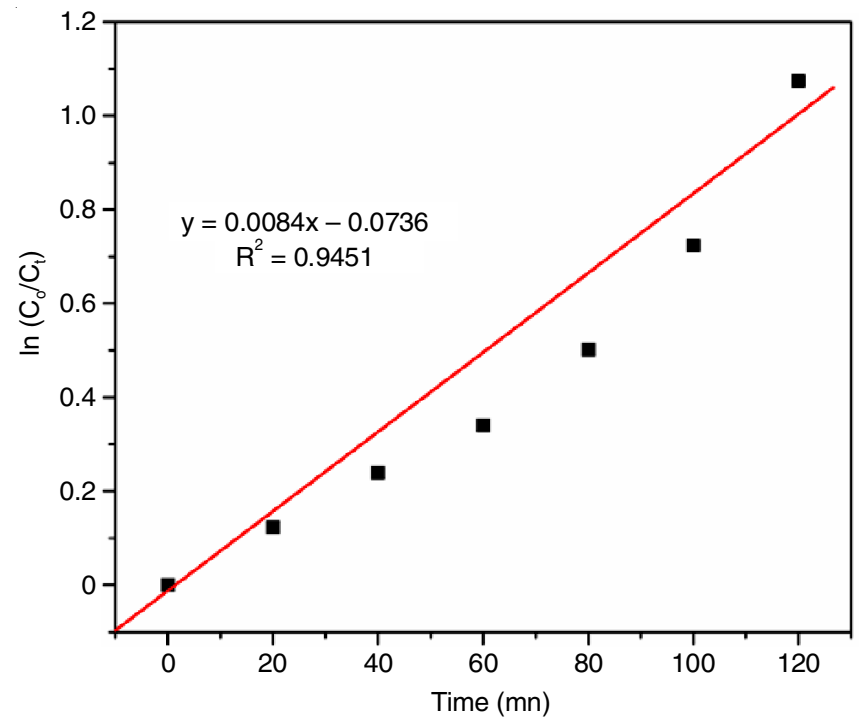

Fig. 8. Rate constant (k) and regression $\left(\mathrm{R}^{2}\right)$ for the pure $\mathrm{CdO}$ nanoparticles

\section{Conclusion}

Nanocrystals of CdO and PEG (2, 4 and $6 \%$ ) assisted $\mathrm{CdO}$ nanoparticles have been successfully synthesized via the co-precipitation method. This is an easy and cost effective tech- 
nique for synthesis of nanoparticles in a large scale and studied for their structural, functional, optical and morphological properties. The XRD results revealed that the prepared nanoparticles were of cubic phase with average crystallite size of $34.86 \mathrm{~nm}$. The existence of functional groups related to $\mathrm{CdO}$ was identified by FTIR measurements. The morphological analysis of cadmium nanostructures showed the presence of mesoporous spherical shaped particles with non-uniform distribution. Finally, the photocatalytic activity of $\mathrm{CdO}$ nanoparticles with methylene blue confirmed that $\mathrm{CdO}$ is a promising catalyst for degrading environmental water pollutants.

\section{CONFLICT OF INTEREST}

The authors declare that there is no conflict of interests regarding the publication of this article.

\section{REFERENCES}

1. T. Trevethan and L. Kantorovich, Nanotechnology, 16, S79 (2005); https://doi.org/10.1088/0957-4484/16/3/015.

2. T. Ahmad, S. Khatoon, K. Coolahan and S.E. Lofland, J. Mater. Res., 28, 1245 (2013); https://doi.org/10.1557/jmr.2013.69.

3. A.T. Ravichandran, A.R. Xavier, K. Pushpanathan, B.M. Nagabhushana and R. Chandramohan, J. Mater. Sci.: Mater. Electron., 27, 2693 (2015); https://doi.org/10.1007/s10854-015-4079-8.

4. H. Sowa and H. Ahsbahs, Z. Kristallogr. Cryst. Mater., 214, 751 (1999); https://doi.org/10.1524/zkri.1999.214.11.751.

5. E. Karaoðlu, T. Ozkaya and A. Baykal, J. Supercond. Nov. Magn., 25, 2403 (2012); https://doi.org/10.1007/s10948-012-1618-x.

6. M. Hekmati, F. Bonyasi, H. Javaheri and S. Hemmati, Appl. Organomet. Chem., 31, e3757 (2017); https://doi.org/10.1002/aoc.3757.

7. S.H. Khan, R. Suriyaprabha, B. Pathak and M.H. Fulekar, AIP Conf. Proc., 1724, 020108 (2016); https://doi.org/10.1063/1.4945228.

8. D.H. Son, S.M. Hughes, Y. Yin and A.P. Alivisatos, Science, 306, 1009 (2004); https://doi.org/10.1126/science.1103755.

9. S. Baruah, S.S. Sinha, B. Ghosh, S.K. Pal, A.K. Raychaudhuri and J. Dutta, J. Appl. Phys., 105, 074308 (2009); https://doi.org/10.1063/1.3100221.
10. Y. Chen, C. Zhang, W. Huang, Y. Situ and H. Huang, Mater. Lett., 141, 294 (2015); https://doi.org/10.1016/j.matlet.2014.11.106.

11. S. Sivakumar, A. Venkatesan, P. Soundhirarajan and C.P. Khatiwada, Spectrochim. Acta A: Mol. Biomol. Spectrosc., 151, 760 (2015); https://doi.org/10.1016/j.saa.2015.06.105.

12. S. Sivakumar, A. Venkatesan, P. Soundhirarajan and C.P. Khatiwada, Spectrochim. Acta A: Mol. Biomol. Spectrosc., 136, 1751 (2015); https://doi.org/10.1016/j.saa.2014.10.078.

13. M. Jothibas, C. Manoharan, S.J. Jeyakumar and P. Praveen, J. Mater. Sci.: Mater. Electron., 26, 9600 (2015); https://doi.org/10.1007/s10854-015-3623-x.

14. S. Sönmezoglu, T.A. Termeli, S. Akin and I. Askeroglu, J. Sol-Gel Sci. Technol., 67, 97 (2013); https://doi.org/10.1007/s10971-013-3054-1.

15. K. Dhanshree and T. Elangovan, Int. J. Sci. Res., 4, 1816 (2015);

16. S.J. Priscilla, K. Sivaji and L. Vimaladevi, AIP Conf. Proc., 1832, 050128 (2017); https://doi.org/10.1063/1.4980361.

17. M.R. Bindhu, M. Jeeva and B.M. Amala, Int. J. Res. Eng. Technol., 5, 285 (2016); https://doi.org/10.15623/ijret.2016.0511046.

18. Y.G. Smeyers, M. Villa and M.-L. Senent, J. Mol. Spectrosc., 191, 232 (1998); https://doi.org/10.1006/jmsp.1998.7626.

19. K.A. Rashid and Q. K. Salh, J. Zankoy Sulaimani-Part A, 18, 155 (2016); https://doi.org/10.17656/jzs.10512.

20. Y. Dou, T. Fishlock, R.G. Egdell, D.S.L. Law and G. Beamson, Phys. Rev. B, 55, R13381 (1997); https://doi.org/10.1103/PhysRevB.55.R13381.

21. K.N. Nigussa and J.A. Støvneng, Comput. Phys. Commun., 182, 1979 (2011); https://doi.org/10.1016/j.cpc.2010.12.027.

22. J. Li, Y. Chen, Y.C. Zhang and J.G. Duan, Adv. Mater. Res., 1035, 321 (2014); https://doi.org/10.4028/www.scientific.net/AMR.1035.321.

23. J.M. Buyck, F. Peyrusson, P.M. Tulkens and F. Van Bambeke, Antimicrob. Agents Chemother, 59, 4750 (2015); https://doi.org/10.1128/AAC.00428-15.

24. W. Huang and W.-L. Yu, Proceedings of the Third Okinaga Symposium on Materials Science and Engineering Serving Society, Materials Science and Engineering Serving Society, Chiba, Japan, 3-5 September, 1997, pp. 261-264 (1998); https://doi.org/10.1016/B978-044482793-7/50060-6.

25. R. Iwai, R. Haruki, Y. Nemoto and Y. Nakayama, J. Biomed. Mater. Res. B: Appl. Biomater, 105, 1009 (2017); https://doi.org/10.1002/jbm.b.33638. 